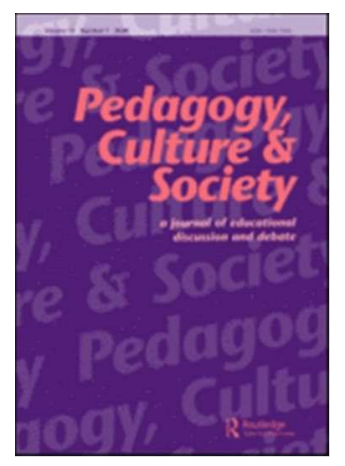

\title{
Soft openings: The psycho-technological expertise of third sector curriculum reform
}

\begin{tabular}{|r|l|}
\hline Journal: & Pedagogy, Culture and Society \\
\hline Manuscript ID: & RPCS-2012-0020.R2 \\
\hline Manuscript Type: & Original Manuscript \\
\hline Keywords: & $\begin{array}{l}\text { curriculum reform, curriculum theory, third sector, governmentality, } \\
\text { pedagogic identity }\end{array}$ \\
\hline \multicolumn{2}{|l}{} \\
\hline
\end{tabular}

SCHOLARONE ${ }^{\text {Ix }}$

Manuscripts 


\title{
Soft openings: The psycho-technological expertise of third sector curriculum reform
}

\author{
Since the late 1990s the "third sector" has become active in generating new curriculum \\ programmes in England. Based on tracing third sector participation in public education \\ during the New Labour years, the article explores a documentary archive of third sector \\ curriculum texts and argues that the programmes, strategies and techniques of the third \\ sector have sought to pursue a new form of governmentality. The type of governmentality \\ pursued by the third sector takes form as a "soft" style of curriculum reform derived from \\ assembling together cybernetic and psychological forms of expertise, interactionist and \\ constructivist pedagogies, and an emerging "psycho-technology" of subjectivity. The third \\ sector fabricates reform proposals for a curriculum of the future in which governance is done \\ by cross-sectoral networking, epistemological categories are blurred, and student \\ subjectivities are made up to be malleable, soft-skilled and psychologically self-shaping. The \\ article examines how third sector texts have assembled this new psycho-technological \\ expertise of curriculum reform through both cybernetic and psychological styles of thinking.
}

Keywords: curriculum reform, curriculum theory, third sector, governmentality, pedagogic identity

\section{Introduction}

This article provides an initial tracing of third sector participation in public education and its proposals for curriculum reform during the New Labour years (1997-2010) in England. In using the term third sector I am referring to a particular New Labour policy construct which advocated the hybridisation of political power and other non-political forms of authority, and especially, as one Cabinet Office report (Maguire 2010) articulated it, the "role of third sector innovation" in “education and learning services." Even within education alone, however, the third 
sector is certainly not a homogeneous sector and it should be noted that the term "third sector" was formally dropped by the incoming Coalition government in 2010 to be replaced by newer policy constructs such as the "Big Society" and by an official government Office for Civil Society, part of the Cabinet Office. Rather than merely a narrow sector mediating between state and markets, however, the third sector, and more latterly the Coalition's civil society, embody the invention of an experimental form of post-bureaucratic politics in which social enterprises, philanthropies, communities, and even individuals themselves (as active citizens) are increasingly encouraged to take responsibility for innovation in public services. The article traces the role of "third sector innovation" in proposing and promoting curriculum reforms, and argues that the heterogeneous programmes, strategies and techniques of the third sector constitute "the pursuit of a type of governmentality" pegged to a rationality of self-regulating individuals (Foucault 2008, 313).

As Ball $(2012,15)$ has recently claimed, "the third sector can be seen as a new governmentality," encompassing subjectivity, institutional practices, economy and government, which has been realised and embedded in "the 'enterprising-up' of public organisations, and the work of charities and voluntary organisations," and in "the growth of 'social enterprise' solutions." The new governmentality of the third sector is constituted by small changes and incremental reforms which work together on systems, organisations and individuals to produce new institutions, practices and subjectivities. As a result, the organisation and the individual are "treated in exactly 
the same way" and "enabled to think about themselves differently," with the "selfmanaging individual" aligned with "the autonomous organisation" (Ball 2012, 31). The third sector curriculum projects on which I focus in this article are parts of this new governmentality - they generate new institutional practices in terms of decentred curriculum delivery and autonomous governance, and produce new subjectivities in the form of soft and malleable self-managing pedagogic identities. Taken together, these practices and subjectivities constitute the soft type of governmentality pursued by the third sector, which is arguably now being further rolled out in the Coalition's Big Society programme. All of this is constituted in a discourse that Thrift (2005, pp. 33-34) describes as "soft capitalism," characterized by complexity, experiential learning, flexibility, networking, by its caring and sharing ethos, its "niceness," its responsibility and its values, and by its generation of a new subjectivity defined as a self-realizing, self-fulfilling and self-regulating individual actor.

\section{Cybernetics and psychology}

The soft governmentality pursued by the third sector works through a style of thinking, or a rationality, that is both cybernetic and psychological. As a "cybernetic style of thought" that saturates contemporary thinking, it mobilises a panoply of technological metaphors, of networks, complexity, connectivity, flexibility, multiplicity, and adaptability (Osborne \& Rose 1999, 750; Thrift 2005). In a 
cybernetics of the school, concepts and metaphors such as networks and flexibility are designed into the institutions and practices of pedagogy, carrying with them affordances which catalyse and foreclose particular actions, experiences and conduct, and which shape particular student subject positions and pedagogic identities (Monahan 2005). Correlatively, a psychological style of thinking deploys new ways of conceiving student subjectivities in terms of their competence, wellbeing, and soft skills. As Foucauldian studies have shown, the discourse and techniques of "psy" in education have a long and complex genealogy, from early modern disciplinary techniques which sought to "correct" children's minds and bodies through "pedagogical machinery," to a "moral orthopaedics" which advocated more child-centred and participatory pedagogies and was largely associated with educational psychology and the "gaze of the psychologist" in the classroom (Deacon 2006; Rose 1999a). Psychological expertise works upon the "calculable future potential of the young" and establishes socially desirable modes of conduct and forms of knowledge by "proactively intervening in their future behaviour" (Deacon 2006, 180) 184). This proactive intervention is especially important since schools have been repositioned by the "new demands for active, multi-skilled and self-regulated citizens" in a global economy (Deacon 2006, 184). That is to say, as Rose (1996) argues, that new ideas of identity, which address, represent and act upon individuals in terms of their own autonomous "projects of identity," psychological interiority, and self-actualisation, have been "assembled" through psy knowledges and authorities working within schools. As such, 
psychological expertise has become increasingly influential in curriculum reform, its rise paralleled by the decline of more critically- and politically-oriented curriculum theory, so that the content knowledge contained in the curriculum is "never just that" but "embodies learning how to see, think, act and feel" according to standards generated by "psychological 'eyes'” (Popkewitz 2012, 177).

The third sector acts as a relay between these cybernetic and psychological ways of thinking, combining them as a psycho-technological expertise of curriculum reform which has as its aim the invention of new pedagogic institutions, new pedagogic practices, and the inculcation of pedagogic identities: subjects to be made up in terms of their own autonomous and self-actualising projects of identity. I use the term "psycho-technology" in two related senses. First, to refer to the connection of psychological and technological metaphors deployed by the third sector. And second, to refer to the ways in which third sector texts promote "innovative" pedagogic practices, techniques, processes and environments which seek to act technically upon the psychology and competence of students. As Rose (1999b, 52-54) has argued, a "technology of schooling" is a hybrid and heterogeneous assemblage of a diversity of objects and relations, including pedagogic knowledges and vocabularies, books, texts and curricular guidance, moral aspirations, environments of a certain design, and myriad techniques and exercises, all assembled together in order to act upon the conduct and capacities of students in the hope of bringing about certain desired effects. A psycho-technology of schooling, then, is likewise 
assembled as a variety of means and techniques for acting upon the psychological capacities of the student. The new psycho-technology of schooling generated by the expertise of the third sector promotes student subjectivities characterized by their flexibility, adaptability, malleability, but most of all by their active and autonomous capacity to be self-shaping and self-managing. The psycho-technological subject assembled and promoted by the third sector is both psychologically and technologically competent, "augmented" within a new type of governmentality with the psychological well-being and self-enterprising qualities required to address the "problem of innovation," as Foucault argued (2008, 231-32).

In order to show how the pursuit of this type of governmentality has been assembled by the third sector, I examine a documentary archive of third sector curriculum texts, including curriculum guides, websites, project reports, and articles by key third sector actors and advocates. These texts act as reform proposals embodying visions and objectives for the curriculum of the future. In these texts, the curriculum is reinscribed in terms of devolved soft governance and soft epistemology, within which students are to be remade as soft subjects. These are discursively continuous with the "soft capitalism" of complexity, experiential learning, flexibility, niceness and networking, in which subjects are made up as selffulfilling and self-realizing (Thrift 2005, 34). To be clear, these forms of soft governance, soft epistemology and soft subjectivity, as proposed and promoted by the third sector, are interdependent pieces of a new way - or perhaps a third way- 
of thinking about reforming the curriculum, rather than as a causal chain of actual events. Drawing on a way of asking questions derived from studies of governmentality (e.g. Rose 1999a; 1999b; Dean 2010), the research asks what the participating third sector organisations wanted to happen to the curriculum, to address what problems, in pursuit of what objectives, and through what strategies, techniques and programmes of intervention. The third sector curriculum projects I describe are by no means homogeneous, and nor are they simple realizations of a dominant neoliberal agenda or other hegemonic attempts to enframe and enclose the future of education. Rather, through shared and eclectic vocabularies, theories, concepts, explanations and ways of thinking that traverse and bisect sectoral, disciplinary and ideological boundaries, they build consensus and legitimacy around the construction of particular problems to which they also offer solutions. The extent to which these discourses actually produce the practices they describe is a matter for further empirical research. Here the focus is rather on the problems and objectives they construct and the curricular solutions they propose and promotethe pursuit of a type of governmentality pegged to a rationality of psychological well-being and cybernetic connectivity, within which pedagogic institutions, pedagogic practices, and pedagogic identities are treated as homologous: soft, open, self-shaping and self-organising.

\section{The research}


The article is based on tracing the participation of the third sector in public education and reports on analysis of a documentary archive produced by third sector organisations. The research treats third sector texts on the curriculum and other educational reform matters as documentary constructions of reality. I adopt tools and methods of a policy discourse and policy network approach to the contemporary study of education reform which emphasises how new educational ideas are created cumulatively from an eclectic selection of fragments, slogans, and recitations of language and concepts that are reiterated and authorised by actors speaking within public education, although they do not necessarily produce a clear and coherent vision of the future but a complex, messy, and sometimes contradictory set of alternatives and dilemmas (Ball 2007; 2012). The analysis is based on bringing together a large number of third sector texts including reports, manifestos, curriculum guidance, pamphlets, articles, and personal essays, alongside website texts and resources such as specific project websites, infographics, diagrams, charts and tables, interactive devices and other multimedia. It shows how these texts or inscriptions cluster and juxtapose a heterogeneous array of ideas, concepts, theories, and their historical and political networks of connections into a new conceptual vocabulary and a set of practical possibilities for acting upon the curriculum (Fenwick \& Edwards 2010). As inscriptions they make the messy future of the curriculum seemingly presentable and representable as "material techniques of thought" which objectify, stabilise and preserve "otherwise ephemeral and subjective visions" (Rose 1999b, 36-37). 
Moreover, the third sector texts articulate at a very minor level the invention of a new technology of schooling - an ensemble of theories, techniques, designs, relations and mechanisms - generated through delicate affiliations and associations between a diverse network of bit-part players, actors and agencies (Rose 1999b). Such innovations are not part of the more elevated top-level curriculum reforms of government departments but the outcome of a variety of non-political organisations, experts and authorities from outside the formal organs of government that are now involved in relaying and translating governmental educational objectives "at a distance" into a diversity of local interventions. My purpose is not to claim absolute coherence across a quite large and fuzzy-edged sample of texts (nor to rush either to judgement or to its defence), but to identify and examine the key concepts, problematisations and specifications for practical reforms it promotes, and to understand the expertise and authority of the network of third sector organisations mobilising it.

In order to place some limits on what data to present in the article, I concentrate on three types of third sector text. The first type consists of specific curriculum programme materials. I examine documents, website materials, guidance and reports from the RSA's Opening Minds project, from the Paul Hamlyn Foundation's Learning Futures programme, and from Futurelab's Enquiring Minds initiative. The second type consists of synthetic reviews, and includes a report on Developing and accrediting personal skills and competence produced by Futurelab and 
commissioned by the QCA; a review of programmes promoting Wider skills for learning produced by the Centre for Real-World Learning and NESTA; and a report on programmes promoting wellbeing entitled The state of happiness produced by the Young Foundation. The third type consists of reform advocacy - booklets and articles setting forth new reformatory visions for the future of education. I make no claims that these texts enframe and foreclose the huge variety of third sector activities. But they do illustrate something of an emerging style of thinking associated with the third sector, and allow us to explore how, as a loose network, it has sought to rework the school curriculum through a psycho-technological expertise of curriculum reform, and to pursue a new type of governmentality constituted by new forms of soft governance, new soft curricular epistemologies, and new soft student subjectivities.

\section{Assembling third sector participation in public education \\ Local centres and crossover expertise}

The participation of the third sector in the curriculum is no transhistorical accident. The third sector has been assembled in contemporary political strategies as the work of political centres of government has been devolved into a multitude of authorities and "local centres of power-knowledge" (Foucault 1990, 98). Instead of bureaucratically organised government acting alone, the powers of the state are now increasingly devolved and refracted through a plurality of other formally 
autonomous bodies and a heterogeneous array of non-political organisations and authorities (Miller \& Rose 2008). These changes are registered in the linguistic movement from government to governance. As recently anatomised by Ball (2007; 2012), governance is understood to catalyse all sectors, public, private and voluntary, as well as the expertise of new cross-sectoral organisations, into partnerships to solve the problems of the polycentric state.

At the same time these developments have also involved the processes by which individual actors have come to construe their own "responsibilised" autonomy, interests, problems and aspirations for the future as intrinsically linked with those of authorities (Rose 1999a; 1999b; Miller \& Rose 2008). Here the job of intermediary "experts" and a proliferation of independent authorities has been particularly important. Experts act as relays between politics and person, forming and managing linkages between "questions of government, authority and politics, and questions of identity, self and person" (Dean 2010, 20). The ways in which individuals think and act, rather than being imputed directly by government, draw upon a multitude of authorities and different forms of expertise, each with its own associations, vocabulary, theories, and ideas, narratives and performers. The delicate affiliations forged between the aspirations and anxieties of individuals and the objectives of government, as channelled through a heterogeneous "ensemble" formed by a multitude of institutions, calculations and programmes, was what Foucault named as governmentality (Foucault 2007, 108). It is into this complex of 
relations between governance, expertise and identities - the field of governmentality - that third sector organisations have been deployed.

In England specifically (less so in post-devolution Scotland, Wales and Northern Ireland) the third sector was assembled as part of New Labour's "third way" reconciliation of central governing bodies and commercial markets. Although it remains theoretically fuzzy and institutionally heterogeneous, it has since the late 1990s moved considerably from the margins to the mainstream in economic, political and social life (Haugh \& Kitson 2007, with many of the approaches it championed being continued in the Coalition's Big Society agenda. Propelled by the intellectually promiscuous and self-consciously iconoclastic "shock tactics" of New Labour thinktanks like Demos (Mulgan 2006, 151-52), and peopled by the expertise of "intellectual workers" who could catalyze, broker and propel its practical, marketable and "vehicular" ideas (McLennan 2004; Osborne 2004), the "decentralised system" of the third sector has been constructed as a "laboratory for new ideas" in a world of perpetual innovation and creativity (Mulgan 2007).

Yet beyond its formal political and organisational constitution, the third sector has also, in Rose's $(1999 b, 189)$ terms, been "made up" as a space of "thought and action." The "community of the third sector" is a "fertile ground for experimentation" and a "moral field" of "emotional relationships through which individual identities are constructed through their bonds to micro-cultures of values and meanings" (171-172, original emphases). A sector has been brought into existence 
that actively constructs certain kinds of problems to be acted upon. It intervenes in such problematisations by deploying techniques and programmes which encourage particular kinds of ways of thinking, seeing and acting; which promote relations and allegiance to specific values, cultures and communities; and which shape and mould particular "active practices of self-management and identity construction" (176).

These techniques and practices seek to install norms and values of individual behaviour and self-conduct via the expertise of more "outsiders" and varied "professionals" in the processes of governing education at a distance (Pykett 2007).

\section{Curriculum entrepreneurs}

The involvement of third sector participants in public education has taken shape against increasingly centralised political control, standardisation and performance criteria in England. Yet at the same time, and somewhat paradoxically, under New Labour the curriculum became the site for a resuscitated (though contested) culture of experimentation characterised for Young $(2008,86)$ by a "softening" and an "opening up" of the curriculum through: (i) the crossing of disciplinary boundaries; (ii) the incorporation of everyday knowledge into the curriculum; and (iii) the involvement of non-specialists in curriculum design. Developments such as Scotland's Curriculum for Excellence, and the "futures" agenda of "personal, learning and thinking skills" advocated by the Qualifications and Curriculum Authority in England are examples of a reformatory agenda that appears to embody a theoretically agnostic mix of both centralisation and devolution, as characterised 
by top-down prescription of centrally defined standards and bottom-up flexibility in practice (Harris \& Burn 2011; Priestley 2011; Priestley \& Humes 2010). Young (1998, 78) anticipated much of this political, historical and theoretical confusion about the "curriculum of the future," which he understood to be an "open system" characterised by connectivity, hybridity, genericism, and flexibility.

The third sector has been highly active in these softening and opening up processes. Various third sector organisations have actively sought to problematise the school curriculum, and to intervene in its future development through the propellant ideas of a new kind of expertise and authority. Rather than the "ivory tower" expertise of curriculum scholars or the "bureaucratic" expertise of curriculum developers and planners within the department of education or one of its delivery agencies, the third sector has set about constructing a series of reform prototypes for a curriculum of the future through the heterogeneous governance of a loose and mobile network of curriculum entrepreneurs, brokers, fixers, catalysts, and innovators from think-tanks, non-profit organisations, charities, and the philanthropic outgrowths of corporations (Morgan 2011; Williamson 2012). The Royal Society of Arts, Manufactures and Commerce (RSA), the National Endowment for Science, Technology and the Arts (NESTA), the Paul Hamlyn Foundation, Demos, the Institute of Public Policy Reform (IPPR), the Innovation Unit, Futurelab, and myriad others, have all sought to position the curriculum as a problem to which they each are able to offer their expert solutions and practical interventions. It is this loose 
and mobile network of organisations I sketch and describe. Their interventions are by no means all equivalent or homogeneous - even within education alone the third sector is not a homogeneous sector-but they are all networked together through interorganisational and cross-sectoral relationships, partnerships and strategic alliances, and moreover, as I shall show, they inscribe their programmes through shared vocabularies, theoretical synergies, and cross-referenced arguments and explanations.

The third sector has participated in attempts to reshape the ways the school curriculum may be understood and thus enacted, which it has done by seeking to reposition its political centres of calculation, multiply and pluralise its centres of authority and expertise, and diversify the local centres of its interpretation and enactment. It has sought to reform pedagogic institutions through soft governance, and to reform pedagogic practices through soft curricular epistemologies. At its most visceral, the soft style of thinking articulated by the third sector may be materialising in the ways learners see, think and act in schools, that is, by "fabricating" or "making up" new pedagogic identities so as to achieve certain future aspirations and objectives (Popkewitz 2008). The rest of this article attempts to grasp some of the ways in which third sector curriculum texts work to generate and promote (if not always quite to enact) a new soft style of governance, soft curricular epistemologies, and the soft subjectivities which constitute this new governmentality. 


\section{Soft governance}

The third sector constitutes itself as a self-consciously experimental site wherein non-educationalist experts are encouraged to participate in the design and promotion of new curricula. The prototype curriculum programmes of the third sector are paradigmatic of soft governance which is achieved through complex negotiations and exchanges between public, private, intermediary and crossover actors, groups, and organisations. The third sector seeks to get things done through "networks" and other "open source" organisational models derived from the web (e.g. McCarthy, Miller \& Skidmore 2004; Mulgan \& Steinberg 2005), and is constituted by cross-sectoral and interorganisational policy networks which hybridise political power and other non-political forms of authority (Williamson 2012). Within the highly "network-conscious" third sector (Osborne 2004), networks "constitute a new form of governance" which brings new voices, sources of authority and discourses into policy thinking and blurs the "boundaries between state, economy and civil society" (Ball 2012, 9).

Opening Minds, Learning Futures and Enquiring Minds are constitutive of third sector network governance strategies. All three are structurally constituted by nongovernmental organisations with direct governmental, quasi-governmental and commercial links. Opening Minds, for example, is operated by the RSA, whose Chief Executive Matthew Taylor is a former advisor to Tony Blair. Learning Futures is cosponsored by the Innovation Unit, which itself originated within the New Labour 
government department for education and has subsequently worked extensively through partnership with commercial and voluntary organisations. And Enquiring Minds was established by Futurelab, which again received core funding from the department and carried out a number of key contracting services for its associated quangos. In addition, Enquiring Minds received all of its direct funding from Microsoft Partners in Learning, a "philanthropic" outreach of the computing corporation, in a very clear cross-sectoral blend of public, private and third sector networking. At the same time all three programmes are made up from overlapping organisational and interorganisational connections and alliances. Staff advise one another's projects, sit on committees and steering groups, present their projects at one another's events, and intertextually cross-reference each other's publications.

The new edu-experts of these organisations bring new kinds of knowledges, legitimised by new kinds of authority, into curriculum reform and the invention of new types of pedagogic institution. Most significantly, the intellectual workers of the third sector have been responsible for deploying a cybernetic expertise which appears to legitimise not only the place of technology in education but the cybernetic reshaping of entire educational institutions and systems. This takes different forms. Opening Minds, for example, is directly influenced by the needs of industry, with its main sponsor, the RSA, a dominant voice in the repositioning of education in terms of enterprise in a post-industrial economy, an agenda it has led for several decades. The Paul Hamlyn Foundation programme Learning Futures also emphasises the 
skills required to "work and thrive as the world grows more interconnected, the environment becomes less stable, and technology continues to alter relationships to information" (Price 2011). Moreover, its project-based learning approach has been developed directly from a partnership with High Tech High (Patton 2012), a Californian network of charter schools assembled by the San Diego Economic Development Corporation and the Business Roundtable to meet the challenges of preparing individuals for the high-tech workforce. Taking a slightly different view on technology, Futurelab endorses the positive value of children's technological and media cultures, and Enquiring Minds is in part a response to the informal digital cultures that are shaping youthful identities. It acknowledges the variety of knowledges that young people access through their own local communities, and through the dispersed communities and experiential expertise accessed through the internet.

In the curriculum documents associated with these projects and organisations, digital knowledge creation spaces, multimodality, smart tools and all manner of digital devices, software and networked gadgets are called into use, most notably in the Enquiring Minds Guide from Futurelab, with its directory of useful web 2.0 devices. Drawing on such examples, an article collaboratively authored by Futurelab and Demos researchers suggests the possibility of a "post-school" digitally networked curriculum. In the "curriculum 2.0" scenario, "schools wither away as young people increasingly learn through networks, drawing on personal and 
domestic digital technologies as sources of learning and ways of connecting with others" (Facer \& Green 2007, 52). The recommendations which follow suggest giving learners control of a "creative portfolio," introducing "peer-to-peer technology tuition," setting up "class wikis," and catalysing "curricular and pedagogic reform" in order to ensure that "soft skills" such as "collaborative learning, personal development, self-monitoring, 'creativity' and 'thinking' skills are developed as a matter of course in schools" (56). These texts promote a cybernetics of school which does not merely advocate for enhanced use of educational technologies but actually seeks to reconstitute schooling itself as a decentred web of learning opportunities in an open access economy within which learning has been delimited, deinstitutionalised and dispersed across the entire lifecycle. In these examples of a cybernetics of schooling, an "actively responsible self" is summoned forth by third sector curriculum texts, a self who is "becoming more active" with greater "capacities to know and to question enhanced by transnational media [and] the internet" (Miller \& Rose 2008, 217).

What is striking is how new technologies and the cybernetic metaphors inscribed to describe them-networks, open systems, DIY media, clouds - act simultaneously as "e-learning" devices and governance devices. To take one example of this hybridisation, Demos and Innovation Unit researchers suggest that the entire education system be remodelled on an "R\&D" process of "open or democratised innovation" in which new ideas are developed through "digital 
networks" and "smarter strategies" that will "search, connect and develop across these much wider and more networked fields" (Bentley \& Gillinson 2007, 16). These smart strategies seek to involve users directly in the design of new services, based on the assumption that as a result "they can be expected to become more active and responsible participants" (17). Third sector interventions are inscribed over and again through network discourses and other cybernetic metaphors which do not just describe pedagogic practices but actively seek to reconstitute pedagogic institutions in a "cloud culture" of "shared projects" and "combinatorial innovations" based on ideals such as "self-managed, user-generated information" and "mashup data" (Leadbeater 2010, 28-29).

\section{Soft epistemology}

The prototypical curricula of Enquiring Minds, Opening Minds, and Learning Futures are based on the idea that the curriculum of the future will consist of new forms of soft knowledge and a view of knowledge as increasingly permeable and hybrid. In such programmes, knowledge boundaries are supposed to have been softened and made malleable, if not erased, and distinctions between academic, vocational and everyday knowledge have been blurred. A few examples illustrate this softening and opening up trend. The Opening Minds programme focuses on the knowledge and skills required for students to be "capable, creative learners, citizens and employees" twinned with the "needs of the economy"; it cultivates the 


\begin{abstract}
"necessary skills to be effective in the world of business and commerce," such as selfmanagement, team working, problem-solving, and independent learning, and encourages students to "plan their work, organise their own time and explore their own ways of learning" (Candy 2011, 285-286).
\end{abstract}

Similarly, Learning Futures proposes an open-ended epistemology of inquiry. Its inquiry pedagogies promote research, experimentation, learning through doing, problem-solving, and evaluating information, and it strongly promotes a thematic and "project-based" pedagogy which involves "designing, planning and carrying out an extended project" using "digital technology" to "conduct serious research, produce high-quality work," and to "foster a wide range of skills (such as time management, collaboration and problem-solving)" (Patton 2012). The Learning Futures approach to curriculum is defined in terms of being "placed," "purposeful," and "pervasive." It reaches, has relevance to, and connects with students' own communities and interests; fosters value and agency and encourages students to act as "protoprofessionals"; and it extends into independent and interdependent informal learning that "matters to students" (Price 2011).

Futurelab's Enquiring Minds also emphasises inquiry as a way of knowing which is necessary in a complex informational environment where it is more important to know how to seek and how to analyse information than to acquire and retain basic knowledge. Enquiring Minds assumes that students possess valuable knowledge and ideas that they are able to bring into the classroom and it aims to 
build upon young people's experiences, ideas, interests and knowledge, particularly their experiences and uses of new media and digital technologies outside school (Morgan, Williamson, Lee \& Facer 2007). The task for teachers in an inquiry classroom is to listen and respond to students, adapting flexibly and fluidly to their interests and questions accordingly. These inquiry pedagogies have a long genealogy, and programmes like Enquiring Minds can be understood as assembling together and reanimating the progressivism of Dewey, the radical pedagogies of Freire, and the de-schooled learning webs and nets of Illich, with the noninstitutionalised cybernetic fantasy of digitally-based learning as radical individualism, self-regulation and freedom from governmental bureaucracy (Selwyn 2010, 130-131).

These examples of student-led inquiry, personal projects and portfolios constitute a new flexible, interactive and dynamic form of pedagogy. In this "flexible interactive pedagogy" teachers are encouraged and expected to elicit and respond flexibly to students' interests, words and actions, and this model of "interactionism constructs both a response-able/-ready child and a response-able/-ready teacher" (Fendler 2001, 132-33). Inquiry learning and interactionist pedagogies are mutually interdependent. The textual inscription of these programmes constructs them as flexible, malleable and boundary-free curricula that can travel anywhere, interactively taking in encounters with knowledges from all areas of experience, from any media, and across disciplines. The curriculum, in these documents, is a co- 
constructed artefact which privileges the idea of students as knowledge builders who are engaged in constructing new knowledge through a variety of collaborations with lay experts and experiential experts sourced through the web.

The hyperlinked, cybernetic curricula of the third sector are epistemologically fuzzy, promoting soft epistemologies crafted around the active "know-how" of "competence" rather than the "know-what" of curricular knowledge. They are informed by a "new language of learning" which is assembled from psychological theories of constructivist, interactive, situated learning and active knowledge construction (Biesta 2006). To this can now be added emerging cybernetic understandings of learning as networked, connected, mobile, flexible, and dispersed across a multiplicity of both formal and informal institutions and pedagogies. Elements of the new psycho-technological language of learning can be found across the textual archive of the third sector. Key promotional documents from the Learning Futures programme, for example, make specific reference to the "nature of learning," "thinking skills," the "psychology of optimal experience," "learning processes, settings and styles," "peer tutors," "learning communities," "effective lifelong learning," "virtual learning" and "visible learning," all of which are proposed to constitute "learning which is deep, authentic and motivational" (Learning Futures 2010; Price 2010).

Furthermore, as the review of competences curricula by Futurelab detailed, many emerging curriculum and pedagogic frameworks (from across all sectors) 
include an "extended project" or "personal challenge" component which is seen as a means of ensuring that learning is meaningful and coherent, and enabling learners to develop "responsibilities," "skills" and "competencies" that could not be developed through other pedagogic approaches. Such personal challenges are characterised in the review documentation as "content-neutral," "authentic," as making a "contribution," and as enabling learners to "make connections across different subject areas and across in-school and out of school learning," as well as between "specialist subjects" and "specialised areas of personal interest," supported by "specialists across and outside the school community" (Facer \& Pykett, 2007, 21). The hybridity of such pedagogies is understood not as originating from pedagogic or epistemological grounds but from its "consistency with the increasingly 'boundary-less' character of modern economies" allied to a "constructivist" view of knowledge (Young 2008, 37).

Again, the appearance of such psycho-technological theories in third sector curriculum thinking is no historical accident. In 1993, the quarterly magazine from the think-tank Demos - one of the key conduits for New Labour thinkingpublished an article on "the future of school" by Howard Gardner, then co-director of Project Zero at Harvard Graduate School of Education. Gardner's article advocated a future of school which emphasises "multiple intelligences," a "studentcurriculum" brokerage service which "helps match students' profiles, goals and interests to particular curricula and to particular styles of learning," and a "school- 
community broker" dedicated to matching opportunities in the community with students' "cognitive profiles," all tasks that he saw then as being supported by ICT (Gardner 1993, 8-9). Gardner's theory of multiple intelligences has since been popularised in British schools. But it is not coincidental that the title of his article for Demos, "Opening Minds," was later made the title of the flagship reform programme from the RSA, which translates Gardner's key ideas into its new competencies curriculum framework. At the very least we need to acknowledge the intermediary role of Demos and the RSA in relaying Gardner's expertise of multiple intelligences and cognitive profiling into British schools. The accompanying Demos editorial suggests an even wider applicability for multiple intelligences in political leadership and styles of governing, perhaps an interesting note in the genealogy of New Labour itself. Profiling students' learning styles through diagnostic surveys, online personal skills tracking, and effective learning inventories are key elements in the Learning Futures ensemble of techniques and reforms too.

It is important to restate that these ideas have not been mandated into schools but, largely through the intermediary work of the third sector, introduced through cumulative clustering, juxtaposition and reiteration across a variety of texts, programmes, and interventions. Opening Minds built upon ideas elaborated in the Gardner essay, and aligned them with the RSA's history of intervention in the future of work, "enterprise education" and "education for capability" to meet the alleged training needs of the knowledge-based economy. Opening Minds offers a 
"competence" curriculum which, as its executive director explains:

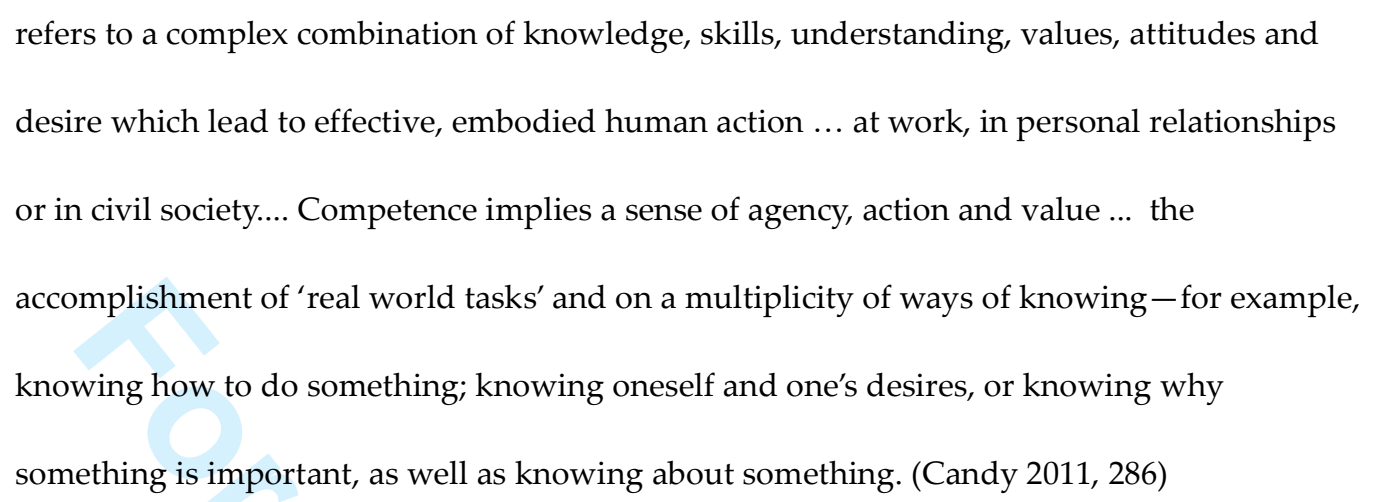

Competence is realized in the form of projects, themes and experiences, with learning inscribed as an active and creative practice. The competence-based curriculum emphasises active learning and creativity; self-regulating learners; a pedagogic discourse of interactionism, inquiry-based learning, projects, themes and experience; learner autonomy over the selection, sequencing and pacing of their learning; and personalisation according to the intentions, dispositions, relations and reflexivity of learners. The theoretical origins of the Opening Minds model of competence lie in the 1960s and 70s, when social scientists and radical educators alike began to celebrate the active, creative, meaning-making potential of individuals. But in programmes like Opening Minds, competence is translated as behavioural competences, constructivism, personal learning profiles, personalised learning, learner reflexivity, "flexible transferable potential," and it emphasises the "ability to be taught" and continuously retrained in a "pedagogised future" of “continuous pedagogic re-formations" (Bernstein 2000, 59). Its “psycho-pedagogy of social competence" is therapeutic and introspective, empowering and emancipatory, 
and it promotes learning "behavioural techniques" of "self-regulation" (Rose 1999a, 243). While Opening Minds is very overtly presented as a competencies curriculum, other programmes like Learning Futures and Enquiring Minds have also catalysed a host of reformatory aspirations around psycho-pedagogic ideals of inquiry, constructivism, project-based learning, and other forms of self-regulative competence.

\section{Soft subjectivity}

Through the texts, guidance and interventions of the new edu-experts of the third sector, teachers have been encouraged to see students in different ways, through such theories as social constructivism, a curriculum of competencies, pedagogies such as interactionism, and techniques such as cognitive profiling, skills tracking and inventorying. These all constitute a new psycho-technology of schooling. In this section, I want to explore a little more the particular form of the pedagogic identity, made up as a certain kind of subject, that is sculpted, inculcated, and promoted by third sector actors "at a distance" from the classroom.

A particularly important set of examples of how learners are being assembled as new sorts of subjects is provided in a series of reviews of curriculum and pedagogic projects conducted by or on behalf of third sector organisations. These reports include a review of frameworks promoting "wider skills for learning" for 
NESTA conducted by the Centre for Real World Learning and the Talent Foundation; a review of "personal skills and competencies approaches" conducted by Futurelab for the QCA; and a review of wellbeing programmes by the Young Foundation entitled The State of Happiness. The NESTA "wider skills" project synthesized a very large number of different "skills frameworks" emerging from government departments, research institutes, private companies, and third sector organisations. Its report on the wider skills required for twenty-first century economies emphasises the importance of "new smarts," "orientations," "capabilities" and "capacities," "dispositions" to learning, and the "mental and emotional habits of mind" which are required "if innovation is to be effectively developed in young people" (Lucas \& Claxton 2009, 4). The "wider skills" report proposes the application of psychological expertise to the economic challenges of the twenty-first century, and identifies methods for cultivating, tracking and measuring the new desirable qualities of "innovation." Young people are positioned by the report as the subjects of psychological discourses of cognitive competence, emotional resilience and therapeutic self-reflection, but recast rather more instrumentally in terms of the composition, augmentation and "investment in human capital" required for “technological innovations" (Foucault 2008, 231-32).

Likewise, the Young Foundation review of projects to promote well-being stresses a strong connection between improving personal well-being and happiness through education and the enhancement of national economic well-being. The report 
proposes that the promotion of "mental capacity" and "mental wellbeing" will be vital for meeting the challenges of a changing society and for ensuring the "mental capital" of the population. The report specifically recommends dedicating school curriculum time to "honing social and emotional competencies," "thinking creatively, collaboration, empathy and emotional resilience," especially so since "wellbeing and resilience matter to employment and to the economy"(Bacon, Brophy, Mguni, Mulgan \& Shandro 2010, 49-50). In the report's almost utopian ideal of a "state of happiness," strategies to ensure economic well-being work from a distance through the therapeutic reflexivity and emotional intelligence of learners, and "[e]motion and capital are now linked productively in a new configuration: emotional capital" (Hartley 2006, 64-65). Foucault (2008, 230-231) showed that the problem of innovation could be solved by making "educational investments" to improve the psychological health of the individual and by such means to augment human capital. The State of Happiness translates the concerns, calculations, strategies and programmes of public policy into the far distant minutiae of individual emotional life, in a process aligning the "objectives of authorities" with the "personal projects" of the individuals and populations who are the subjects of those authorities (Rose 1999b, 48).

In the reports for NESTA and the Young Foundation economic values of action, adaptability, entrepreneurship, excellence, flexibility, innovation, initiative and so on can be released through pedagogic institutions and practices that promote 
psychological values of human autonomy, happiness, well-being, values, and creativity. Schools are positioned in these reports to inculcate and promote psychological habits of mind and emotional capital, to encourage learners to "become a psychologist" in their own projects of identity, incorporating its vocabularies into their own ways of speaking, its gaze into their ways of looking, and its practices into their ways of acting (Rose 1996, 123) -in short, fabricating subjects who see through "psychological eyes" (Popkewitz 2012, 177). In promoting curricular alternatives like Opening Mind, Enquiring Minds and Learning Futures, the third sector assembles an understanding of the learner who is to be psychologically armed and pedagogically prepared with the social and emotional competencies and skills required for innovation in a future characterised by constant rapid technological and economic change. Their autonomous projects of identity have been shaped both "instrumentally" as a response to economic and technological currents and "therapeutically" in the "open narratives" and "personal projects" of oneself and one's desires, in order to inculcate "prospective pedagogic identities" which can "deal with cultural, economic and technological change" (Bernstein 2000, 73 original italics). A homology has been constructed between young people's own projects of identity and the prospective pedagogic identities which are shaped through the curriculum. This is, indeed, as the title of the Young Foundation report suggests, a perfect "state of happiness."

Additionally, in drawing extensively on metaphors such as networks, open 
systems and clouds, these prospective pedagogic identities are made up in an empowering cybernetic discourse of self-organisation, active participation, open access and self-regulation. These cybernetic assumptions about the liberating, democratising and emancipatory potential of new technologies and media are juxtaposed with constructivist styles of psychological thinking into a messy and heterogeneous theoretical "mashup" in which subjectivities are assembled as open systems perpetually self-upgrading through interaction in dynamic networks. The interactive, constructivist identity fabricated in the third sector psycho-technology of the curriculum of the future is a contingent improvisation of self-centred psychological discourse and cybernetic discourses, together with specific resources and materials including tools for measuring and monitoring one's learning dispositions and the digital devices required for learning online. In sum, the "mashed up" identities (Fenwick \& Edwards, 2010, 168) being constructed through the psycho-technological curriculum of the future are simultaneously prospective, projective and prosthetic:

- Prospective: being oriented to the future, able to deal with social and technological change, able to constantly retrain.

— Projective: being psychologically self-competent, constructivist, selfupgrading, with one's own identity as a personal project.

— Prosthetic: being networked, flexible, interactive, interdependent, connected, and extended into a hyperlinked universe of the web. 
The new pedagogic identity shaped by third sector participation in public education is articulated prospectively into anticipated futures which require new competences for innovation; projected through a range of personal projects into the psychotechnics of competency self-management; and reticulated prosthetically through networked technologies into the hyperlinked knowledge practices of the web.

\section{Conclusion}

The third sector has been shown to be an experimental site for the invention of new innovations in public services that harnesses the energies and ideas of a variety of new non-political authorities within public education itself. In this article I set out to trace the pursuit of a type of governmentality by third sector educational organisations and actors constituted by a "cybernetic style of thinking" and a new "soft capitalist" discourse of complexity, experiential learning, flexibility, and networking. It has begun to outline how such a soft, cybernetic governmentality is inscribed in third sector texts in terms of an assemblage of pedagogic institutions, pedagogic practices and pedagogic identities discursively reworked and reconstituted as soft governance, soft epistemology and soft subjectivity. Within these discourses, diverse forms of expertise, practical knowledges, vocabularies, forms of authority, objects and devices have been assembled, clustered and hybridised. The third sector mobilises styles of thinking that are both cybernetic and 
psychological. Assembled together as a psycho-technological style of thinking about schooling, these elements promote a soft subject who is malleable, adaptable and flexible, able to remould and resculpt his or herself, through continuous and digitally dispersed pedagogic opportunities and experiences, according to a continuous analysis of the fit between personal life trajectory and the technological, economic and cultural contingencies of the future. The third sector style of thinking assembles a prospective pedagogic identity which is continually self-sculpting through personal projects, whether literally in the personal challenges set forth in the curriculum or figuratively in their lifelong projects of personal identity.

The ideal autonomous, self-regulating learner inscribed by the third sector, however, is no historical accident but specifically fabricated. The proposed curriculum of the future envisioned and inscribed in third sector texts is to be the product of an array of new authorities and forms of expertise which are brought into schools through the network governance of cross-sectoral alliances, and which claim a knowledge of the new innovative needs of the market, the valences of networked ICT, and the psychological nature, capacities and competencies of the individual. The alignment of new technological practices and new psycho-technical methods for acting upon learner competence have been combined in its proposals for new types of curriculum, new forms of school knowledge, and the making up of new kinds of emotionally capable, interactive subjects. It is through assembling together, juxtaposing and clustering its ideas about new forms of governance, new 
epistemologies, and new subjectivities, that the third sector has sought to pursue a new type of governmentality, a governmentality in which pedagogic institutions and pedagogic practices and pedagogic identities are presupposed as homologous - as networked, self-regulating, and self-organising. It is the fabrication of this set of homologies of softness and malleability that this article has begun to trace, outline and describe, though at this stage the examination has remained confined to text and the inscription of proposals and objectives rather than reporting on empirical observation. More needs to be done to get "inside" third sector innovation ethnographically, in order to examine the extent to which inscription and discourse has been translated in practice. With current shifts in political discourse from the third sector to the Big Society much more in-depth research also needs to be done to more fully understand the participation of non-political authorities, think-tanks, social enterprises and other hybrid organisations in education change, and to grasp the implications for changing pedagogic institutions, reforming pedagogic practices, and reshaping pedagogic identities.

\section{References}

Bacon, N., Brophy, M., Mguni, N., Mulgan, G. \& Shandro, A. 2010. The State of Happiness: Can public policy shape people's wellbeing and resilience? London: Young Foundation.

Ball, S.J. 2007. Education plc: Understanding private sector participation in public sector education. Abingdon: Routledge.

Ball, S.J. 2012. Global Education Inc. New policy networks and the neo-liberal imaginary. Abingdon: Routledge.

Bentley, T. \& Gillinson, S. 2007. A DER system for education. London: Innovation Unit..

Bernstein, B. 2000. Pedagogy, Symbolic Control and Identity, $2^{\text {nd }}$ ed. Oxford: Rowman \& Littlefield.

Biesta, G. 2006. Beyond Learning: Democratic education for a human future. London: Paradigm. 
Candy, S. 2011. Opening Minds: A curriculum for the $21^{\text {st }}$ century. Forum 53, no. 2: 285-291.

Deacon, R. 2006. Michel Foucault on education: a preliminary theoretical overview. South African Journal of Education 26, no. 2: 177-187.

Dean, M. 2010 Governmentality: Power and Rule in Modern Society, $2^{\text {nd }}$ ed. London: Sage.

Facer, K. \& Green, H. 2007. Curriculum 2.0: Educating the digital generation. In Unlocking Innovation: Why citizens hold the key to public service reform, edited by S. Parker \& S. Parker. London: Demos.

Facer, K. \& Pykett, J. 2007. Developing and accrediting personal skills and competences: Report and ways forward. Bristol: Futurelab.

Fendler, L. 2001. Educating Flexible Souls: The Construction of Subjectivity through Developmentality and Interaction. In Governing the Child in the New Millennium, edited by K. Hultqvist \& G. Dahlberg, 119-142. London: RoutledgeFalmer.

Fenwick, T. \& Edwards, R. 2010. Actor-Network Theory in Education. Abingdon: Routledge.

Foucault, M. 1990. The Will to Knowledge: The History of Sexuality: Volume I. Trans. By R. Hurley. London: Penguin.

Foucault, M. 2007. Security, Territory, Population: Lectures at the Collège de France, 1977-1978. Edited by M. Senellart, trans. By G. Burchell. New York: Palgrave Macmillan.

Foucault, M. 2008. The Birth of Biopolitics: Lectures at the Collège de France, 1978-1979. Edited by M. Senellart, trans. By G. Burchell. New York: Palgrave Macmillan.

Gardner, H. 1993. Opening minds. Demos Quarterly, 1, Winter 1993: 1-11.

Harris, R. \& Burn, K. 2011. Curriculum theory, curriculum policy and the problem of ill-disciplined thinking. Journal of Education Policy 26, no. 2: 245-261.

Hartley, D. (2006) The instumentalization of the expressive. In Schooling, Society and Curriculum, edited by A. Moore, 151-161. London: Routledge.

Haugh, H. \& Kitson, M. 2007. The third way and the third sector: New Labour's economic policy and the social economy, Cambridge Journal of Economics 31: 973-994.

Leadbeater, C. 2010. Cloud Culture: The future of global cultural relations. London: Counterpoint/British Council.

Learning Futures. 2010. Learning Futures: Engaging schools. London: Paul Hamlyn Foundation/ Innovation Unit.

Lucas, B. \& Claxton, G. 2009. Wider Skills for Learning: What are they, how can they be cultivated, how could they be measured and why are they important for innovtation? London: NESTA.

Maguire, A. 2010. The Role of Third Sector Innovation: Personalisation of education and learning services. London: Cabinet Office.

McCarthy, H., Miller, P. \& Skidmore, P. (eds). 2004. Network Logic: Who governs in an interconnected world? London: Demos.

McLennan, G. 2004. Travelling with vehicular ideas: the case of the Third Way. Economy and Society 33, no. 4: 484-499.

Miller, P. \& Rose, N. 2008. Governing the Present: Administering Economic, Social and Personal Life. Cambridge: Polity.

Monahan, T. 2005. Globalization, Technological Change, and Public Education. Abingdon: Routledge.

Morgan, J. 2011. Enquiring Minds: A radical curriculum project? Forum 53, no. 2: 261-272.

Morgan, J., Williamson, B., Lee, T. \& Facer, K. 2007. Enquiring Minds: A Guide .Bristol: Futurelab. 
Mulgan, G. 2006. Thinking in Tanks: The Changing Ecology of Political Ideas. The Political Quarterly 77, no. 2: 147-155

Mulgan, G. 2007. Ready or not? Taking innovation in the public sector seriously (London: NESTA).

Mulgan, G. \& Steinberg, T. 2005. Wide Open: Open source methods and their future potential. London: Demos.

Osborne, T. 2004. On mediators: Intellectuals and the ideas trade in the knowledge society. Economy and Society 33, no. 4: 430-447.

Osborne, T.S.D. \& Rose, N. 1999. Governing cities: Notes on the spatialisation of virtue. Environment and Planning D: Society and Space, 17: 737-760.

Patton, A. 2012. Work that matters: The teacher's guide to project-based learning. London: Paul Hamlyn Foundation.

Popkewitz, T. S. 2008. Cosmopolitanism and the Age of School Reform: Science, education, and making society by making the child. Abingdon: Routledge.

Popkewitz, T.S. 2012. Numbers in Grids of Intelligibility: making sense of how educational truth is told. In Educating for the Knowledge Economy? Critical perspectives, edited by H. Lauder, M. Young, H. Daniels, M. Balarin \& J. Lowe, 169-191. Abingdon: Routledge.

Priestley, M. 2011. Whatever happened to curriculum theory? Critical realism and curriculum change. Pedagogy, Culture and Society 19, no.2: 221-237.

Priestley, M. \& Humes, W. 2010 The development of Scotland's Curriculum for Excellence: amnesia and déjà vu. Oxford Review of Education 36, no. 3: 345-361.

Price, D. 2010. Learning Futures: Engaging students. London: Paul Hamlyn Foundation/Innovation Unit.

Price, D. 2011. Learning Futures: rebuilding curriculum and pedagogy around student engagement. Forum 53, no. 2: 273-284.

Pykett, J. 2007. Making citizens governable? The Crick Report as governmental technology. Journal of Education Policy 22, no. 3: 301-319.

Rose, N. 1996. Inventing Our Selves: Psychology, power, and personhood. Cambridge: cambrudge University Press.

Rose, N. 1999a. Governing the Soul: The shaping of the private self, $2^{\text {nd }}$ ed. London: Free Association Books.

Rose, N. 1999b. Powers of Freedom: Reframing Political Thought. Cambridge: Cambridge University Press.

Selwyn, N. 2011. Schools and Schooling in the Digital Age: A critical analysis. Abingdon: Routledge.

Thrift, N. 2005. Knowing Capitalism. London: Sage.

Williamson, B. 2012. Centrifugal schooling: Third sector policy networks and the reassembling of curriculum policy in England. Journal of Education Policy, iFirst: http://dx.doi.org/10.1080/02680939.2011.653405

Young, M.F.D. 1998. The Curriculum of the Future: From the 'new sociology of education' to a critical theory of learning. London: Falmer Press.

Young, M.F.D. 2008. Bringing Knowledge Back In: From social constructivism to social realism in the sociology of education. Abingdon: Routledge. 